[Recommendation]

\title{
弛豫时间分布法分解固体氧化物燃料电池电化学阻抗谱
}

庄林

武汉大学化学与分子科学学院, 武汉 430072

\section{Decomposition of Solid Oxide Fuel Cell Electrochemical Impedance Spectra by Distribution of Relaxation Time Method}

\section{ZHUANG Lin}

College of Chemistry and Molecular Sciences, Wuhan University, Wuhan 430072, P. R. China.

Email: lzhuang@whu.edu.cn

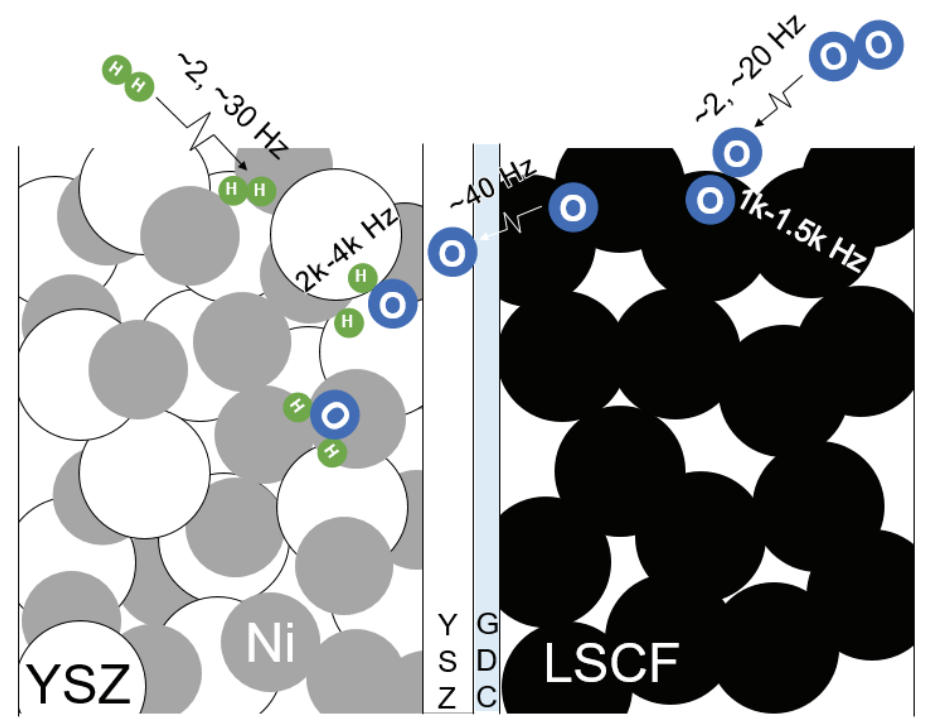

固体氧化物燃料电池阻抗谱中不同电化学过程对应的特征频率响应。

电化 学交流阻抗谱 (Electrochemical Impedance Spectrum, EIS)是非常实用的电化学表 征技术之一, 被广泛地用于科学研究当中。其工 作原理是在很宽的频率范围内 $(\mathrm{mHz}-\mathrm{MHz})$ 获得一 个小电流/电压偏置信号的响应特性 ${ }^{1}$, 据此信息可 以获得不同时间尺度下发生的物理、电化学过程, 包括物质运输、反应动力学甚至热力学过程等 ${ }^{2}$ 。 通过解析EIS数据确定反应历程, 并获得相应参数 的定量值(即扩散系数, 反应速率常数等) 是阐明反 应过程本质的基础。用于解析EIS数据的最常用方 法是等效电路模型法(Equivalent Circuit Method,
$\mathrm{ECM})$ 。但是这种方法存在明显的不足, 即同一个 阻抗谱能够用多个等效电路拟合 ${ }^{3}$, 拟合过程缺乏 科学的理论支撑。

近年来, 弛豫时间分布法 (Distribution of Relaxation Time, DRT)开始得到越来越多的研究 ${ }^{4-6}$ 。 该方法将一系列的电化学反应与相应的弛豫时间 一一关联，弛豫时间分布的统计结果能反映实际 电化学反应的主次情况。德国卡尔斯鲁厄理工学 院Ivers-Tiffée团队在固体氧化物燃料电池 ${ }^{4}$ 和锂离 子电池 ${ }^{7}$ 领域发展并成功应用了此种方法。对于燃 料电池来说，阻抗谱中包含的信息有欧姆阻抗和 
极化阻抗; 极化阻抗还可以细分为阳极活化极化 阻抗、阳极浓差极化阻抗、阴极活化极化阻抗和 阴极极浓差极化阻抗四种, 而获得上述阻抗数值 的准确大小是研究燃料电池性能和稳定性的关键 步骤8。清华大学能源与动力工程系韩敏芳等人根 据固体氧化物燃料电池中的极化理论基础, 系统 设计了阻抗的差异化研究实验方案, 成功地分解 出Ni-YSZ|YSZ|GDC|LSCF型燃料电池中六个特征 的物理和电化学过程, 其中 Ni-YSZ (Ni-Yttria Stabilized Zirconia, 氧化钇稳定氧化锆) 为阳极, YSZ为电解质, GDC (Gadolinia Doped Ceria, 氧化 钝掺杂氧化铈) 为隔离层, LSCF $\left(\mathrm{La}_{0.6} \mathrm{Sr}_{0.4} \mathrm{Co}_{0.2} \mathrm{Fe}_{0.8} \mathrm{O}_{3-\delta}\right)$ 为阴极。最终又基于 DRT结 果, 确定了该电池的等效电路并予以拟合, 计算 出各过程的阻抗占比。

该工作已在物理化学学报上在线发表 (doi: 10.3866/PKU.WHXB201806071) ${ }^{9}$ 。该文章实验方 案设计可靠, 从改变温度到改变阴、阳极气体组 分(改变有效氧分压), 为电池的DRT结果提供了科 学、可靠的数据基础。而且该工作贯穿了阻抗差 异分析法、弛豫时间分布法和等效电路拟合法, 为 燃料电池的阻抗谱研究提供了一条完整的分析方 法, 具有广泛的普适性, 可以为燃料电池的阻抗 谱研究提供指导。

\section{References}

(1) Orazem, M. E.; Tribollet, B. Electrochemical Impedance Spectroscopy; John Wiley \& Sons: Hoboken, New Jersey, USA, 2011. doi: $10.1002 / 9781119363682$

(2) Schmidt, J. P.; Manka, D.; Klotz, D.; Ivers-Tiffée, E. J. Power Sources 2011, 196 (19), 8140. doi: 10.1016/j.jpowsour.2011.05.047

(3) Lasia, A. Electrochemical Impedance Spectroscopy and Its Applications; Springer: German, 2014. doi: 10.1007/978-1-4614-8933-7

(4) Schichlein, H.; Müller, A. C.; Voigts, M.; Krügel, A.; Ivers-Tiffée, E. J. Appl. Electrochem. 2002, 32 (8), 875. doi: 10.1023/a:1020599525160

(5) Leonide, A.; Sonn, V.; Weber, A.; Ivers-Tiffée, E. J. Electrochem. Soc. 2008, 155 (1), B36. doi: 10.1149/1.2801372

(6) Schoenleber, M.; Ivers-Tiffée, E. Electrochem. Commun. 2015, 58, 15. doi: 10.1016/j.elecom.2015.05.018

(7) Schmidt, J. P.; Berg, P.; Schönleber, M.; Weber, A.; Ivers-Tiffée, E. J. Power Sources 2013, 221, 70. doi: 10.1016/j.jpowsour.2012.07.100

(8) Ploner, A.; Hagen, A.; Hauch, A. Fuel Cells 2017, 17 (4), 498. doi: 10.1002/fuce. 201600193

(9) Shi, W. Y.; Jia, C.; Zhang, Y. L.; LÜ, Z. W.; Han, M. F. Acta Phys. -Chim. Sin. 2019, 35 (5), 509. [施王影, 贾川, 张永亮, 吕泽伟, 韩敏芳. 物理化学学报, 2019, 35 (5), 509.] doi: 10.3866/PKU.WHXB201806071 